\title{
Consideraciones sobre un marco metodológico encaminado al análisis de textos*
}

\section{Considerations on a methodological framework for the analysis of texts}

\section{Considerações sobre um quadro metodológico encaminhado à análise de textos}

\author{
Ángel David Roncancio García** \\ David Andrés Camargo Mayorga*** \\ Nataly Marcela Muñoz Murcia**** \\ Cómo citar: Roncancio, A.D., Camargo, D.A., \\ Munoz, N.M. (2017) Consideraciones sobre un \\ marco metodológico encaminado al análisis de \\ textos. Sophia, 13 (1): 109-121.
}

\begin{abstract}
**Docente investigador de tiempo completo de la Facultad de Ciencias Económicas, miembro del grupo de estudios contemporáneos en contabilidad, gestión y organizaciones, y del grupo GECS, Universidad Militar Nueva Granada. Correo electrónico: angel.roncancio@unimilitar.edu.co

***Docente investigador de tiempo completo de la Facultad de Ciencias Económicas miembro del grupo de estudios contemporáneos en Contabilidad, Gestión y Organizaciones Universidad Militar Nueva Granada. Correo electrónico: david. camargo@unimilitar.edu.co

****Asistente de investigación, vinculada al proyecto ECO 1481, integrante del grupo GECS. Licenciada en Lengua Castellana y Humanidades. Universidad Distrital Francisco José de Caldas. Correo electrónico: tmp.nataly.munoz@unimilitar.edu.co
\end{abstract}

\section{Resumen}

El artículo presenta una revisión de literatura pertinente para la construcción de un marco metodológico para el análisis de textos en ciencias sociales aplicadas, como las ciencias económicas, la cual hemos apoyado en los principales enfoques hermenéuticos provenientes de la filosofía, la lingüística y de las ciencias sociales. En esencia, estos asumen que todo discurso es portador de significado -sea este veraz o no- y que expresan complejas relaciones sociales. Así entonces, cualquier análisis de contenido, pasa por ser en últimas un cierto tipo de hermenéutica (interpretación), en tanto que intenta dar cuenta de múltiples fenómenos inmersos en la producción, aplicación, uso y reproducción del saber al interior del texto. Al aplicar el análisis de discurso en textos de enseñanza en ciencias económicas encontramos rastros de discursos legalistas, políticos, tendencias etnocentristas, entre otros discursos ocultos al texto. Por lo cual el análisis del discurso interno del texto permite adentrarse al interior de la ideología de estado y de sus discursos subyacentes o latentes.

Palabras clave: Análisis de textos, enfoques hermenéuticos, libros de texto, metodologías de análisis crítico del discurso.

\section{Abstract}

This article presents a review of relevant literature for the construction of a methodological framework for the analysis of texts in applied social sciences, such as economics, which we have supported in the main hermeneutical approaches from philosophy, linguistics and social sciences. In essence, they assume that every discourse carries meaning - be it truthful or not - and that they express complex social relations. Thus, any analysis of content happens finally to be a certain type of hermeneutics (interpretation), while trying to account for multiple phenomena immersed in the production, application, use

*Producto derivado del proyecto de investigación titulado "Didácticas y prácticas docentes en la enseñanza de la contabilidad fundamental en programas acreditados en Alta Calidad en Bogotá" (ECO 1481) financiado por la Vicerrectoría de Investigaciones de la Universidad Militar Nueva Granada- vigencia 2014. 
and reproduction of knowledge within the text. When applying discourse analysis in teaching texts in economic sciences, we find traces of legalistic, political, ethnocentric tendencies, among other discourses hidden from the text. For this reason, the analysis of the internal discourse of the text allows us to delve inside the state ideology and its underlying or latent discourses.

Key words: Analysis of texts, hermeneutical approaches, critical discourse analysis methodologies, textbooks.

\section{Resumo}

O artigo apresenta uma revisão da literatura relevante para a construção de um quadro metodológico para a análise de textos em ciências sociais aplicadas, como as ciências econômicas. Esta revisão baseia-se nas principais abordagens hermenêuticas provenientes da filosofia, a linguística e as ciências sociais. Em essência, estas assumem que todo discurso é portador de significado $\neg$ seja este verídico ou não-, e que expressa complexas relações sociais. Neste sentido, qualquer análise de conteúdo, parece ser, afinal, certo tipo de hermenêutica (interpretação), na medida em que tenta dar conta de múltiplos fenômenos imersos na produção, aplicação, uso e reprodução do saber no interior do texto. Ao aplicar a análise de discurso em textos de ensino em ciências econômicas encontramos vestígios de discursos legalistas, políticos, tendências etnocentristas, entre outros discursos ocultos ao texto. Por isto, a análise do discurso interno do texto permite entrar no interior da ideologia de estado e dos seus discursos subjacentes ou latentes.

Palavras- chave: análise de textos, abordagens hermenêuticas, metodologias de análise crítico do discurso, livros de texto

\section{Introducción}

El presente texto pretende construir un marco metodológico para el abordaje del análisis de contenido en general y posteriormente en particular en los textos de enseñanza, pero para ello es necesario elaborar una revisión de literatura de los principales antecedentes teóricos y metodológicos de desde las posturas hermenéuticas que han sido propias de la Filosofía occidental y desde las distintas disciplinas modernas que han tratado el problema de la interpretación más o menos crítica del contenido de diversos discursos, lo cual abarca desde los discursos religiosos, políticos educativos e ideológicos.

A pesar de las sutiles pero en algunos casos profundas diferencias de intencionalidad de cada corriente metodológica, el análisis de textos, conocido como ACD (análisis crítico del discurso), o denominado análisis textual, y en otras ocasiones llamado dependiendo del autor- análisis de discurso; constituye uno de los principales recursos de análisis cualitativo de recursos tanto bibliográficos (textos, y en general documentos escritos) como de actos de habla de significado social en la actualidad. Esta denominación de "método" de análisis de contenido o de análisis de textos, es una pretensión la verdad histórica que proviene en especial de la filosofía y de la sociología moderna de mediados del siglo XX. Sin embargo, aún se discute si el análisis de contenido en textos o discursos es un método en cuanto tal o si es una técnica metodológica, o meramente una herramienta o instrumento.

Para efectos de nuestra investigación asumiremos el uso de ciertas técnicas de análisis de contenido, pues como veremos cada una de las corrientes actuales ofrece elementos válidos a tener en cuenta, aunque sea necesario revisar más adelante la siguiente hipótesis que planteamos: Si bien todo análisis de contenido, es un análisis de discurso. Más allá de los intereses particulares de cada perspectiva metodológica, lo que está en juego es una hermenéutica del texto. Una posibilidad de interpretar de manera crítica tanto los contenidos como las relaciones sociales que producen, configuran y legitiman su uso.

La estructura que proponemos como apuesta de lectura, en primer lugar abordaremos los antecedentes de las teorías de análisis del discurso, en donde haremos una breve mención a las apuestas filosóficas de la antigüedad y de su revitalización en la filosofía del lenguaje más recientes que han visto en la obra de Platón y Aristóteles los antecedentes del análisis del discurso moderno y de sus implicaciones en la lingüística y en la filosofía hermenéutica.

La segunda sección pretende describir los enfoques y posturas metodológicas sobre las relaciones entre Texto y sociedad: y los agencias entre autor, texto y lector, enfoques que permiten conocer los textos en 
su arquitectura interna y situarlos en los contextos sociales e históricos que están por fuera del texto (extra-textuales) para comprender mejor y de una manera más amplia la génesis de sus contenidos estas perspectivas tienen una clara connotación metodológica y en su gran mayoría pertenecen al denominado estructuralismo hermenéutico.

La tercera sección corresponde al camino de la hermenéutica filosófica del s. XX propuesta por el enorme impacto de la obra de Martin Heidegger. Esta propuesta es crítica con respecto al estructuralismo y plantea que tales posturas no nos ofrecen elementos de comprensión de preconceptos, prejuicios, valoraciones, juicios estéticos, actitudes hacia el texto, y pareciera que el sentido mismo queda por fuera de las metaestructuras. Dado que tales constructos esconden el sentido de los textos o de las acciones humanas. Es por ello que la hermenéutica Heideggeriana se encamina hacia el concepto de aplicación, o a la apreciación valorativa del intérprete.

La cuarta sección se adentra en el trasfondo metodológico de las diversas herramientas desarrolladas para el análisis crítico del discurso aplicadas en lingüística, análisis de contenido textual, la ideología política y de estado, entre otros usos, cuyos principales representantes son Teun Van Dijk, Tzvetzan Todorov, y Louis Althusser para quienes es necesario el método estructuralista y formalista para postular el análisis crítico del discurso y el análisis la ideología subyacente.

Para finalizar, la última sección cierra nuestra hipótesis inicial acerca de la posibilidad de aplicar las diversas formas del análisis crítico del discurso en el análisis de textos de enseñanza en ciencias económicas y sugiere la necesidad del uso de los enfoques hermenéuticos para desentrañar los diversos contextos y capas de las posturas teóricas e ideológicas de estas disciplinas económicas que se manifiestan en los libros de texto usados para su enseñanza y reproducción.

\section{Antecedentes del análisis del discurso}

El camino del análisis de contenido (siempre referido a que un texto es un discurso) tal y como se entiende en la actualidad, sale a la luz en los albores del siglo XX, pero es solo después de la Segunda Guerra Mundial, que adquiere interés para las ciencias sociales el estudio de los discursos inmersos en variadas representaciones, que van desde los panfletos hasta los libros de enseñanza, pasando por la publicidad gráfica, radial y multimedia de las sociedades modernas.

Esto no quiere decir que anteriormente no se haya hecho un análisis del contenido de los textos, de hecho, los antecedentes de tal actividad están inmersos en la filosofía de la antigüedad, se encuentran en Parménides, Platón y Aristóteles, como sus principales representantes. En la Grecia clásica se desarrollaron las bases de las ciencias de orden cualitativo que buscaban depurar tanto la estructura del lenguaje (gramática), el uso correcto del lenguaje (lógica), y la posibilidad de aplicación del mismo sin importar si el discurso era escrito o se transmitía simplemente de manera verbal (retórica). Son estos tres tipos de saberes los que sientan las bases para lo que se denomina habitualmente como el análisis de contenido -análisis de textos o análisis de discurso ${ }^{1-}$ (Vattimo, 1991). Por otra parte, en el ulterior desarrollo de estas tres disciplinas, se encuentra posiblemente la diferenciación al interior de las propuestas metódicas en la actualidad.

Esta discusión refleja las tensiones metodológicas y disciplinares especialmente en la intencionalidad de cada propuesta, dado su alcance, uso y posibilidades en contextos tan variados como la lingüística, las ciencias sociales, las ciencias políticas y económicas; pues si bien para algunos estudiosos lo principal es detectar las estructuras subyacentes al texto (o al discurso mismo), para otros, lo esencial es la determinación de la construcción lógico-semántica del texto o discurso, o determinar las relaciones entre el discurso inmerso en el texto y sus dinámicas de poder, y en algunos casos este análisis da cuenta de diferentes intereses que apuntan a determinar los procesos cognitivos y psicológicos, inmersos en la producción de un texto.

El punto en común de estas perspectivas modernas consiste en que todas reconocen que el discurso es portador de significado -veraz o no-, y por demás, expresa complejas relaciones sociales que se manifiestan en el plano de lo político con mayor o menor efecto. Este tipo de lugares comunes no son totalmente nuevos, ya que precisamente este era el interés de Aristóteles en la Retórica, al construir una

1. De aquí en adelante vamos a utilizar los términos discurso y textos de manera indiferenciada, pues para efectos de esta propuesta investigativa, el libro de texto contiene un discurso en particular. Por otra parte, las técnicas metodológicas no plantean mayor distinción, ni siquiera en el uso de los dos términos. 
retórica capaz de detectar las dimensiones ocultas del poder político en la antigüedad y de cómo estar preparado para evitar las truculentas dimensiones del discurso en general. Lo que sí podemos agregar es que las categorías de análisis de lo social son muy distintas y es esto, lo que vamos a explorar con cautela.

Ahora bien, es preciso mencionar que el análisis de contenido se trata de una técnica de investigación característica del ámbito de la sociología del conocimiento, en otros términos, de la dinámica socio-cultural. El origen del análisis está en Freud (2004) y en la psicología interpretativa de comienzos del siglo XX, lo cual derivó en el análisis conceptual de formas simbólicas, tan importante en la obra de Ernst Cassirer y Carl Gustav Jung. En este sentido la obra de Louis Althusser reconstruye en perspectiva como el problema de la ideología interna a los discursos tiene un antecedente metodológico claro en Marx y Freud aunque limitado o pobre dado su alcance metodológico plagado de sentidos no inscritos en el discurso social Althusser (2005).

A partir de la década del treinta surgen las primeras investigaciones de carácter empírico en muestras más amplias, que condujeron al desarrollo de las actuales técnicas de análisis de contenido en discursos y en textos. Este momento es importante para el desarrollo de este tipo de estudios gracias en buena medida a la confluencia de varios elementos sociales. Entre ellos, el rápido desarrollo de los llamados medios de comunicación como la prensa escrita, la radio, el cine y la televisión; también el aumento de la importancia concedida a la opinión pública; la extensión creciente de la propaganda política y de la publicidad comercial, entre otros factores (López, 1963).

En la medida en que florece una esfera social muy diversa y rica que tiene impacto en la cultura, la sociedad y los individuos, es claro que aparecen nuevos objetos de estudio para el análisis de contenido. Pues un cuerpo de comunicación cualquiera puede ser susceptible de ser analizado interno y de incluso determinar la intencionalidad del discurso subyacente. Por ejemplo, una novela de ciencia ficción, un filme de temática tendenciosa, una colección de comics americanos de la Segunda Guerra Mundial, el guion de una telenovela sobre la vida de un narcotraficante, o simplemente, en un discurso político o religioso o en la propaganda de guerra de la Alemania nazi. Es decir, prácticamente todos los sistemas socioculturales son susceptibles de ser analizados en tanto contenidos de discurso. Esto es así, porque el análisis de contenido revela un complejo entramado de significaciones propias del acto comunicativo.

Como cualquier técnica de investigación, hay debate acerca de su eficacia, la validez del tipo de análisis cualitativo o cuantitativo que se use, el alcance de los muestreos en estudios realizados, la validez de los estudios de caso o particulares tan frecuentes en los análisis de contenido, entre otros tópicos, los cuales por cuestión de pertinencia no son de interés en este artículo.

El desarrollo ulterior del documento se organiza así: primero, se abordan los principales referentes de la Análisis Crítico del Discurso (ACD), lo mismo que sus aportes y principales derroteros en la actualidad, el alcance de estos enfoques de carácter estructuralista en el análisis de textos y discursos; en segundo lugar, se abordan algunas de las perspectivas sociológicas del análisis de textos, sus implicaciones antropológicas, etnológicas y el alcance de las mismas; y tercero, se aborda el camino hermenéutico proveniente de la filosofía heideggeriana, el cual cuestiona y a la vez abre la posibilidad de interpretar el texto, lo cual es posible en medida que un sujeto es capaz de darle significado.

\section{Texto y sociedad: autor, texto y lector}

Una de las corrientes derivadas de los trabajos de la postura crítica, se encamina a vincular los contenidos de los textos (tratados como obras, productos humanos con un fin determinado de antemano por el autor) con los momentos históricos de la sociedad que los produjo. Como ya vimos no es que este aspecto fuera desentendido para nuestro referente anterior, lo que pasa es que no es el criterio más importante en principio, es más bien el fin hacia el cual debe llegar el análisis crítico de contenido (Hart, 2007). En primer lugar, este tipo de posturas proceden de Aristóteles (2011), quien pone en juego el problema de la filosofía crítica al leer a sus predecesores y categorizar su pensamiento en periodos, momentos y problemas filosóficos. Lo cual es claro en casi toda su obra, pero especialmente en la Retórica, y en la Metafísica.

Lo que plantea esta postura es conocer los textos en su arquitectura interna y situarlos en los contextos sociales e históricos que están por fuera del texto (extra-textuales) para comprender mejor y de una 
manera más amplia la génesis de sus contenidos. Esto implica que el actor principal del texto (el autor) vuelve a escena por su contexto. Esta perspectiva ha sido alimentada desde influencias variadas pero con el problema de la intersubjetividad y del contexto como fondo común. Uno de los referentes que más ha permeado esta postura socio-histórica es Goldman (1968), y por otra parte, desde una corriente mucho más formalista con Bajtín (1975).

Esto supone que si bien reaparece el autor en el juego comunicativo, no hay que desprenderle del texto mismo ni del lector. El análisis descriptivo de tales elementos, es por ejemplo de interés para investigaciones sobre textos de enseñanza disciplinar (contabilidad, administración, entre otros). Veamos ahora como se caracterizan estos cuatro elementos:

El autor ha de considerarse como un individuo bastante peculiar, porque logra colocarse por encima de procesos individuales y logra expresar a través de un corpus coherente y lleno de significado, la conciencia integral de un grupo social. Además el autor logra expresar mejor que otros miembros del grupo esa conciencia colectiva. La tesis de Goldman (1968) en "El hombre y lo absoluto" es que un texto, un libro de enseñanza, expresa una concepción del mundo, una Weltanschauung ${ }^{2}$. Pero esta consideración centrada en la figura del autor no debe tomarse tan literalmente, pues el autor al sobresalir como individuo excepcional, lo que hace es convertir en meros objetos a los individuos corrientes. Lo cual es en principio la manifestación de ejercicios o prácticas de poder a través de los textos, que posiblemente es una característica en especial de los libros de texto o libros de enseñanza.

En este sentido se encuentra, el modelo texto-mundo de De Beaugrande (1980) y De Beaugrande y Dressier (1981), el cual propone que la relación de conocimiento de un texto en la mente está compuesta tanto por el conocimiento activado en las expresiones textuales como por el conocimiento que se posee del mundo en que se desarrolla quien analiza.

El texto desde esta mirada socio-histórica puede adquirir variadas formas: un libro, una cartilla, un panfleto, una carta amorosa, un grafiti, una partitura, cualquier documento escrito. Es una creación polivalente que necesita ser estudiada en todos los estados posibles, ya desde su percepción estética,

2. Cosmovisión o visión del mundo. hasta su estructura implícita. Es así que el texto mismo se convierte en un objeto empírico que reúne las características físicas de presentación, diagramación, tamaño, uso de colores, gráficos, ilustraciones, etc. Y una serie de características internas como su contenido temático, uso de recursos pedagógicos, volumen, distribución, dispersión, y argumentación.

Por su parte el lector (también receptor) es quien valida tanto la existencia como la reproducción y permanencia del texto. Ello no quiere decir como enuncia Moreno (2007) que sea un actor competente que interviene en todo momento con el texto, y mucho menos que le da sentido en todo momento, pues un buen ejemplo de ello, sucede en el caso de los libros de texto o enseñanza. En donde vemos que no necesariamente el lector a quien va dirigido este tipo de textos, sea competente para dar un juicio de valor adecuado acerca del contenido de un libro o de su estructura argumentativa, o en general de emitir un juicio epistemológico, lo cual puede suceder solo desde una postura autoreflexiva del lector que solo tras una extensa experiencia con diversos textos puede llegar a ello.

Lo indudable es que el lector nunca permanece neutro ante el texto, pues desde su primer acercamiento, ya está formando esencialmente juicios estéticos sobre este. En este orden de ideas, Iser (1987) en el "Acto de leer" plantea que el lector-receptor se encuentra tan implicado con el documento que lee, que es él quien activa en el texto lo que desea obtener de él.

Es la interpretación que hace el lector-receptor, quien descubre los significados ocultos o explícitos del texto, la que le lleva a distanciarse en determinado momento del escrito para reformular su juicio o simplemente reconstruirlo. Es de esta manera, en que se generan las explicaciones que dan cuenta de la significación social del libro de texto. En otras palabras, es en este campo donde se encuentra la conexión entre el contenido del texto y la conciencia de un grupo social (ideología) en un momento histórico particular, en la creación del juicio.

El contexto por su parte destaca los elementos externos que afectan tanto la generación del texto como su reproducción y permanencia. Aunque también da cuenta de otros elementos colectivos que intervienen en la obra en medio de un periodo histórico particular y un referente incluso geográfico. Estos elementos colectivos tienen que ver con las clases sociales que dirigen los procesos de producción académica 
(en nuestro caso particular), también los procesos económicos, los grupos de poder que legitiman el uso y consecución de determinados contenidos al interior de los textos, costumbres de grupos sociales, élites intelectuales que dominan un campo en particular, grupos sociales que defienden o atacan alguna postura en beneficio de otra, etc.

Desde la perspectiva sociológica de Bourdieu (1995) en su texto Las reglas del arte el análisis y reconstrucción del contexto se da por la emergencia del campo, es decir, una construcción libre del ambiente social e histórico que influye de manera directa en la producción de una obra (texto) en una época y lugar específicos. A manera de ejemplo, respecto a los textos de enseñanza contable, desde la perspectiva de Bourdieu (1995), son un tipo de obras que se pueden asumir como textos argumentativos, por lo cual es imperioso estudiar la manera en que el campo de conocimiento emerge y en especial, los motivos (intencionalidades) subjetivos del autor. Ello aclararía la cuestión por la génesis de este tipo de textos, ya que al reconstruir el campo, se estarían hallando las relaciones de acercamiento o distanciamiento del texto analizado con la sociedad de la cual es contemporáneo. Aun así, esta perspectiva puede ser complementada con un planteamiento hermenéutico que dé razón, ya no de las estructuras formales y contextuales del texto, sino de una interpretación crítica del contenido en tanto que sus significados implícitos tienen valor más allá de su uso o legitimación.

\section{El camino hermenéutico}

Si bien el referente más útil en nuestro caso es Martin Heidegger (2000), debemos reconocer la multiplicidad de trabajos sobre la aplicación de un método hermenéutico en el análisis de textos. Lo importante de esta perspectiva es que cualquier análisis de contenido, pasa por ser en últimas un cierto tipo de hermenéutica (interpretación), en tanto intenta dar cuenta de múltiples fenómenos inmersos en la producción, aplicación, uso y reproducción del saber al interior de los textos. De ello se desprende -lo cual vale la pena tener con anterioridad- que al hablar de método hermenéutico debemos entender que método es pura posibilidad de comprensión. Más que un conjunto de reglas determinadas, es una búsqueda constante de dar sentido, un abrir camino que se encaja dentro de la existencia misma.
Una vez hecha esta prevención, en términos generales, la hermenéutica trata de comprender los textos en sus múltiples significados, en tanto que en ellos se expresan las ideas sobre y acerca de un objeto a través de las expresiones de un sujeto en particular, vinculando la intención del autor con la del lector.

Así, un posible método hermenéutico se inicia con una pregunta interpretativa o por la posibilidad de interpretar el texto, la cual requiere una respuesta guiada por un juicio de carácter interpretativo que bien puede referirse a un texto (entendiendo por ello el escrito o el acto de habla mismo) o incluso las acciones humanas tal y como se plantea en Heidegger (2000). De hecho, todo lo que contiene significación, no lo posee de manera inmediata y clara, aún cuando es susceptible de interpretación. Lo cual es posible en medida que un sujeto es capaz de darle significado al texto.

Es de esta manera que un posible método hermenéutico, es en últimas el desarrollo y la realización efectiva de la comprensión, lo cual nos lleva a afirmar que apostar por una posibilidad de interpretación, no necesariamente es afirmar lo comprendido, sino que expresa el desarrollo de las múltiples posibilidades de la comprensión humana. Según Beuchot (1999), el proceso interpretativo implica tres instancias en particular.

- Busca el significado textual, intratextual e intertextual.

- Explica las conexiones entre el texto y los objetos de significado.

- Su aplicación (facticidad), entendida como la manera de detectar la intencionalidad del autor que está implícita en el texto.

Este planteamiento de indudable corte heideggeriano nos deja entrever los problemas del análisis textual o de contenido desde las posturas estructuralistas, que en el fondo pierden campo de trabajo al abandonar la objetividad del campo simbólico del texto, pues si bien desde el estructuralismo podemos elaborar ciertas coordenadas de trabajo sobre el corpus simbólico del texto, no da cuenta de los posibles conflictos de interpretación que igual son válidos, quedando exclusivamente en la postura analítica de las estructuras de reproducción o ya bien de contenido del texto. Es decir, tales posturas no nos ofrecen elementos de comprensión de preconceptos, 
prejuicios, valoraciones, juicios estéticos, actitudes hacia el texto, y pareciera que el sentido mismo queda por fuera de las metaestructuras.

Para Heidegger (2000) la comprensión del sentido desde la hermenéutica, es de carácter globalizante, pues debe dar cuenta de la totalidad de los elementos, no solo de los armazones que esconden o amparan el sentido de los textos o de las acciones humanas. Es por ello que la hermenéutica Heideggeriana se encamina hacia el concepto referencial de aplicación, es decir, hacia la apreciación valorativa del intérprete. Esto es expresado en ontología como la "Hermenéutica de la facticidad", lo cual puede entenderse como que: "En las múltiples posibilidades de darse las cosas, vemos los modos de expresarse el ser en cuanto ser" (Heidegger, 2000: 43), por eso se concluye que el ser no habla, dice; y por tanto, es susceptible de ser interpretado.

La interpretación del texto siguiendo desde este enfoque hermenéutico parte del fundamento ontológico, en donde la realidad no se conoce, solo se interpreta parcialmente y no de manera absoluta, es decir, está en constante interpretación. Esto es lo que se denomina el método hermenéutico. Por tanto, la realidad es interpretada pero no entendida en sus diferentes manifestaciones o sustratos. El ser inmerso en el discurso se manifiesta de múltiples maneras (perspectivas), por lo que la hermenéutica es en últimas el cómo se interpretan las realidades. De este modo, es posible afirmar desde esta perspectiva que lo que es común en todos, y más aún al abordar un texto, es que interpretamos el mundo en sus diferentes capas (sustratos). Bien sean para textos que expresan discursos instrumentales, simbólicos, poéticos, etc.

Esta comprensión de la hermenéutica se encamina, nada menos que a comprender lo que dice el ser, en cualquier caso, reconociendo las limitaciones ontológicas de cualquier investigación en el campo fáctico, se tratará de comprender una parcela del ser (realidad ontológica) ello en medida que interpretar es la condición de la existencia, que es en últimas la dimensión ontológica de cualquier investigación sobre el texto.

Una hermenéutica de la facticidad es posible en medida que tengamos a nuestra disposición los siguientes elementos: Un "haber" previo, esto es, un corpus organizado de textos o de acciones susceptibles de interpretar, lo cual pasa por el reconocimiento de la tradición del saber anterior, el cómo se nos revela y el cómo lo captamos en la actualidad; implica también reconocer los modos de darse la significatividad (actitudes hacia el texto, definiciones normativas, operaciones de significación, valoraciones sobre el contenido, reconocimiento del texto en el campo del conocimiento al cual pertenece, características formales del mismo, una estructura básica del tipo de texto); por último, es necesario dar cuenta de la importancia de la cotidianidad del texto, esto es, de su facticidad, su aplicación y uso en un campo de conocimiento, en donde el horizonte de fáctico es la historicidad inmersa en el texto. A partir de esta propuesta de hermenéutica de la facticidad, como lo menciona Norka Viloria (2001) se desprenden un análisis de corte positivista, intersubjetivo y de carácter analógico, entre otros.

\section{El análisis crítico del discurso y la ideología subyacente}

Uno de los principales exponentes de la corriente crítica de análisis de discurso es Teun Van Dijk (1989, 1996, 2005), quien durante los últimos 40 años ha explorado, y por otra parte, definido los linderos del análisis de discurso desde intereses puramente formales desde el estructuralismo, pasando por la semiótica del discurso, el análisis de la ideología, hasta sus implicaciones en la esfera de lo político:

El análisis ideológico del lenguaje y del discurso es una postura crítica ejercida ampliamente entre estudiosos de las humanidades y las ciencias sociales. Este análisis supone que es posible poner "al descubierto" la ideología de hablantes y escritores a través de una lectura minuciosa, mediante la comprensión o un análisis sistemático, siempre y cuando los usuarios 'expresen' explícita o inadvertidamente sus ideologías por medio del lenguaje u otros modos de comunicación. A pesar de la generalización de estos supuestos y prácticas, no se ha explicitado suficientemente la teoría que relaciona al discurso con estas ideologías subyacentes". De hecho, en los estudios del discurso, así como en la psicología social y cognitiva o en las ciencias sociales, no se sabe gran cosa acerca de cómo exactamente se desarrollan las ideologías a través del discurso, y de qué modo controlan o influyen a los textos y al habla. (Van Dijk; 1996:189).

Este tipo de análisis tiene su origen en el estructuralismo, corriente interpretativa que tiene diversas vertientes en antropología y etnología con Claude Levi-Strauss (2006) como su mayor 
representante, junto a Todorov (1996) quien elabora propuesta para el análisis del símbolo y de la estructura de los cuentos y leyendas europeas, hasta llegar a los discursos de propaganda política que rodearon el agitado siglo XX. Tanto uno como otro, se alejan de las concepciones funcionales de la estructura, proponiendo que la sociedad está compuesta en unidades básicas de la cultura que se presentan en la mente de los individuos de cada sociedad por medio del lenguaje y sus representaciones, pues tales estructuras del lenguaje humano son equivalentes a las de la sociedad. Es necesario mencionar, que están compuestas por oposiciones binarias: naturaleza-cultura, hombre-mujer, etc. que podemos ver y analizar en los diferentes discursos como los mitos y las leyendas, dado que son constructos visibles, son consideradas como conceptos de nuestra mente que se manifiestan en los contenidos discursivos y en la vida social de las diversas culturas (Herrero, 2002).

El estructuralismo de mediados del siglo XX también da origen a los modernos modelos interpretativos del discurso y del texto, como el Modelo jerárquico de Meyer (1984, 1985) el cual está basado en la estructura lógica de textos, de lo que se puede inferir que la superestructura interna del texto es la guía hacia la comprensión. Este modelo da importancia a la relación entre los conceptos de los textos y a la jerarquía de la información.

Otro modelo interpretativo estructuralista es el Modelo narrativo de Rumelhart (1977) y Thorndyke (1977). En donde la estructura del discurso se establece desde un conjunto organizado de manera jerárquica que está compuesto por componentes del discurso narrativo, bajo unas reglas, teniendo en cuenta el esquema narrativo usado para la comprensión y representación producto de los textos narrativos. Discurso narrativo cuyas reglas tienen en cuenta el esquema de esta tipología textual usado para la comprensión y representación producto de dichos textos.

Bajo este surge el llamado modelo situacional de Kintsch-Van Dijk, (1983) el cual es un modelo más comprensivo y estratégico. Estratégico, cuyo presupuesto precisa trabajar con operaciones cognitivas flexibles y no con reglas. $\mathrm{Y}$ en avance con el modelo jerárquico, incorpora un modelo de situación que completa toda información y así permite una mejor comprensión del significado del discurso.
El giro de los análisis de contenido hacia lo sociopolítico será de nuestro interés en tanto nos da un marco teórico más amplio, al considerar al análisis del texto como un tipo específico de análisis del discurso sociopolítico. Es entonces consecuente que: "Dichos análisis, entre otras cosas, pretenden relacionar las estructuras del discurso con las estructuras sociales" (Van Dijk; 1996:56). De manera que solo así, las relaciones sociales de clase, género pueden ser asociadas sistemáticamente con unidades estructurales, niveles, o estrategias de habla y de texto incorporadas en sus contextos sociales, políticos y culturales. Lo cual evidentemente es válido para las relaciones entre organizaciones sociales, instituciones, grupos, roles, situaciones, relaciones de poder o la toma de decisiones políticas, y las estructuras del discurso. Esta línea de análisis ha sido desarrollada por otros especialistas (Bradac, 1999, 2002; Fairclough, 1989, 1992; Kedar, 1987; Kramarae, Schulz y O’Barr, 1984; Kress, 1985; Wodak, 1989, 1996, 2011).

La cuestión subyacente es si la estructura social misma pueda afectar directamente al texto y al habla, lo cual se puede dar de muy variadas maneras, ya que los grupos y las instituciones, en tanto tales, no escriben, ni hablan o comprenden el discurso, sino que lo hacen únicamente por la mediación de agentes comunicantes como miembros de grupos o de categorías sociales. El giro propuesto por Van Dijk (2005) acepta que una nueva articulación teórica donde lo social y lo discursivo puedan "encontrarse" y establecer una relación explícita entre sí.

Esta articulación es la interacción social misma en situación. El discurso así entendido, no solo nombra o da referencia, también crea realidades, y por supuesto, construye y trasmite ideologías. Ahora bien, hay varios tipos de discursos, entre los más importantes, están los discursos públicos. Son en efecto importantes porque es gracias a ellos que los grupos dominantes tienen acceso a grandes poblaciones, por distintos canales como lo son la televisión, la radio y en general la prensa escrita, además, contribuyen bastante en la formación de creencias en los individuos. Pero dentro de estos discursos públicos, encontramos uno bastante particular: el escolar, el cual tiene efecto sobre distintas comunidades sociales, si tenemos en cuenta que la población escolar está compuesta por niños y adultos en rango etario, género o condición social muy amplios. 
Es de esta manera que los discursos al interior de la escuela, la secundaria y la educación superior en general, contribuyen de manera directa a la adquisición de cierto tipo de conocimientos, entre ellos los sociales y culturales, y por medio de sus currículos ocultos contribuye a la transmisión de ideologías dominantes relativas al género, la raza o la condición social (Van Dijk, 2003a, 2003b).

En cuanto a la estructura del discurso, Van Dijk (2005) parte del contenido semiótico y sintáctico del discurso como elementos centrales (una semántica discursiva), ello en medida que la coherencia del texto está definida por dichas características. Pues aún cuando podamos dar cuenta de algunos elementos propios del contexto del discurso, es necesario exigir del análisis una formulación más clara de tales instituciones, y también especificar qué expresiones o significados del discurso dan lugar a qué clase de inferencias $u$ otros procesos mentales. En suma las estructuras se pueden organizar de la siguiente manera:

Tabla 1. Estructuras del discurso

Estructuras fonológicas (tensión, picos, volumen, entonación).

Estructuras gráficas (encabezados, caracteres en negritas).

El ordenamiento y el tamaño generales (primero y después, más alto/más bajo, más grande o más pequeño, preponderancia e inferioridad).

Estructuras sintácticas (el orden de las palabras, la topicalización, las relaciones de cláusulas: principal y subordinada, frontal o encastrada; construcciones divididas).

Estructuras semánticas (explícito vs. implícito, detalle y nivel de descripción, macroestructuras semánticas vs. detalles).

Estilo léxico (palabras de opinión positivas $v s$. negativas).

Retórico (sobre y subestimación, eufemismo, repetición).

Esquemas o superestructuras (expresadas en categorías convencionales prominentes, por ejemplo, encabezados o conclusión, relato y argumentación).

Pragmático (aserción contra negación; autocomplacencia vs. acusación).

Interactivo (autoselección y predominancia; mantenimiento y cambio de tópicos; comunicación no verbal: rostro, gestos)

Fuente: elaboración propia a partir de Van Dijk (2005).

Este conjunto de elementos de análisis da una primera característica a considerar: el estilo léxico y la intencionalidad del texto, lo que además ofrece pistas sobre cuál es el carácter de significado que está implícito en el mismo. En esta misma línea, la segunda característica de utilidad, es que vislumbra los momentos retóricos de la argumentación, ya que una descripción de los mismos, puede dar idea de los recursos a los cuales el autor (o autores) deben echar mano para argumentar unos contenidos.

La tercera característica a seguir es la que define la estructura formal del texto, es decir, los esquemas o superestructuras explicitas, como la caracterización de las unidades temáticas del escrito, las introducciones o prólogos y el uso de espacios eminentemente de ayuda pedagógica.

Una última mención hacia la postura "crítica" de esta corriente investigativa hace necesario recordar, que si bien en sus comienzos hubo una relación de varios de sus exponentes con la escuela crítica de Frankfurt, ni siquiera para Van Dijk $(1989,1996)$ es claro el referente crítico, el cual relaciona con la postura "el espíritu crítico" que debería poseer toda academia. Wodak y Meyer (2003) recuerdan que los analistas críticos del discurso, bien deben reconocer que Habermas ya había recogido al menos el problema desde una postura 'crítica', cuando planteó que: "El lenguaje es también un medio de dominación y una 
fuerza social. Sirve para legitimar las relaciones del poder organizado. En medida en que las legitimaciones de las relaciones de poder no estén articuladas (...) el lenguaje es también ideológico" (Habermas, 1997:76).

De esta manera Althusser (2005) menciona que el "mecanismo" de la ideología en general se reducía a ciertos principios contenidos en pocas palabras tan "pobres" en su sentido y significado tanto como los autores le dan, como las que definen según Marx la producción en general, o en el caso de Freud el concepto de inconsciente en general:

En efecto, el Estado y sus aparatos sólo tienen sentido desde el punto de vista de la lucha de clases, como aparato de lucha de clases que asegura la opresión de clases y garantiza las condiciones de la explotación y de su reproducción. Pero no existe lucha de clases sin clases antagónicas. Quien dice lucha de clase de la clase dominante dice resistencia, rebelión y lucha de clase de la clase dominada (Althusser; 2005: 34).

\section{Consideraciones finales para el análisis de textos en ciencias económicas}

Si bien los libros de texto han sido considerados tradicionalmente como los depositarios del saber y la cultura, esta noción es propia de la modernidad, de hecho, su antecedente prototípico es nada menos que la Didáctica Magna (1626) de Juan Amos Comenio, el libro de texto que impone todo un modo de expresar, replicar y legitimar el conocimiento.

Además de ser valorados como ejes medulares de las prácticas docentes, son imprescindibles para muchos profesores a los que les resultaría muy difícil hacer posible el desarrollo práctico del currículo sin ellos. Pero es solo en la modernidad que aparece lo que llamamos el "libro de texto" o libro de enseñanza usado en la escuela, y en los centros universitarios aun a la fecha de hoy.

Esto implica que existen estructuras subyacentes en el libro de texto que permean su intencionalidad y su ser en términos heideggerianos. Gimeno encuentra en el uso de libro de texto una particularidad: "Porque seguramente a través de ellos (los libros de texto) pervive una metodología pedagógica muy bien asentada, unos intereses económicos y unas pautas de control eficaz sobre la escolaridad"(Gimeno, 1994: 4) de tal forma que, el libro de texto configura el currículo, las prácticas pedagógicas, los discursos, las ideologías, los imaginarios y posiblemente las conductas de quienes los usan.

Permitiéndonos la licencia de traer a colación nuestra hipótesis inicial, todo análisis de contenido, es un análisis de discurso. Más allá de los intereses particulares de cada perspectiva metodológica, lo que está en juego es una hermenéutica del texto. Una posibilidad de interpretar de manera crítica tanto los contenidos como las relaciones sociales que producen, configuran y legitiman su uso.

Así entonces, los actuales estudios sobre el contexto interno de los textos de enseñanza nos permiten entrever desde discursos ocultos, y también currículos ocultos en la intencionalidad y el uso de ciertos libros de texto. Lo cual es evidente en ciertos aspectos de las ciencias económicas como las ideologías subyacentes a ciertas teorías económicas y a las ideologías políticas de sus contextos de producción. En este sentido "En la medida en que el texto domina currículos, ignorarlos como si simplemente no merecieran atención y una lucha seria, equivale a vivir en un mundo divorciado de la realidad". (Apple; 1989: 108).

Este interés tiende a determinar tanto tendencias como influencias al interior de los textos que no son identificables de manera evidente. Siguiendo este enfoque Roncancio y Camargo (2013) analizaron los prólogos e introducciones de textos de enseñanza en contabilidad, encontrando que algunos de estos elementos estaban ocultos, como ciertos discursos legalistas, influencias de conglomerados económicos, nacionalismos y tendencias arcaicas de la profesión contable, al igual que otras ideologías políticas y sociales.

Pero no podemos dejar de lado el aspecto didáctico del uso de libros de texto en las ciencias económicas, pues es muy extendido su uso y diversos sus fines, en el caso de la enseñanza en contabilidad, es casi indispensable y a pesar de En el plano discursivo el docente acepta la importancia de la formación conceptual y epistemológica, sin embargo, cuando trata de hacer esta tarea no resulta clara su estrategia de aproximación (León \& Roncancio, 2008) De esta manera, tal como lo plantea Bourdieu se da un proceso de "reproducción" (Bourdieu \& Passeron; 1972)

En este orden de ideas, Althusser (2005) encuentra que el análisis del discurso interno del texto permite adentrarse al interior de la ideología de estado (que incluye ideologías políticas) para lo cual es 
indispensable tener en cuenta no sólo la distinción entre poder de Estado y aparato de Estado, sino también otra realidad que se manifiesta junto al aparato (represivo) del Estado, pero que no se confunde con él. A lo que se denomina como "los aparatos ideológicos de Estado" latentes en los discursos.

Los libros de texto usados por los docentes en ciencias económicas (administración, economía, contaduría pública, finanzas) tiene un correlato interno que se justifica por diversas razones sociales, políticas e ideológicas, y en el caso de los libros de texto, dado que por excelencia son aquellos que se concentran en el aprendizaje de un buen número de habilidades prácticas de la contabilidad financiera, por ejemplo, o de la microeconomía, de los costos, o de la matemática financiera. Así que las estructuras temáticas os capítulos o apartes de tipo teórico son más bien escasos o accesorios. De esta manera: "El docente no encuentra un correlato entre lo que pide el modelo de evaluación y lo que se establece en los textos generalmente usados" (León \& Roncancio; 2008: 75).

Ante esta situación, los docentes pueden estar retornando a un modelo tradicional de educación en la cual la enseñanza se refiere a la reproducción textual y al discurso institucional o corporativo que reproduce tanto los textos como los discursos y contenidos. Donde ya sea por principio de autoridad o experiencia, se vuelven textos de uso común, y se mantienen en el tiempo tanto como sea necesario para el discurso económico hegemónico o el de los intereses de los agentes económicos que rodean el contexto del texto mismo.

En medida que florece una esfera social muy diversa y rica que tiene impacto en la cultura, la sociedad y los individuos, es claro que aparecen nuevos objetos de estudio para el análisis de contenido. Pues un cuerpo de comunicación cualquiera puede ser susceptible de análisis de su contenido interno y de la intencionalidad del discurso subyacente. Por ejemplo, una novela de ciencia ficción, un film de temática tendenciosa, una colección de comics americanos de la Segunda Guerra Mundial, el guion de una telenovela sobre la vida de un narcotraficante, o simplemente, en discurso político o religioso, en la propaganda de guerra de la Alemania nazi. Es decir, prácticamente todos los sistemas socioculturales son susceptibles de ser analizados en tanto contenidos de discurso. Esto es así, porque el análisis de contenido revela el contenido manifiesto de las comunicaciones.

\section{Referencias bibliográficas}

Althusser; L. Ideología y aparatos ideológicos de estado: Freud y Lacan. Nueva Vision Argentina, Buenos Aires.

Apple, M. (1989) Maestros y Textos. Una economía política de las relaciones de clase y de sexo en educación. Paidós: Barcelona.

Aristóteles. (1998). Retórica. Madrid: Alianza Editorial.

(2011). Metafísica. Buenos Aires: Random House Mondadori.

Bajtín, M. (1975). Teoría y estética de la novela. Madrid: Taurus.

Beuchot, M. (1999). Perfiles esenciales de la hermenéutica: hermenéutica analógica. México: Instituto de investigaciones filológicas. UNAM.

Bourdieu, P. (1995). Las reglas del arte. Barcelona: Anagrama.

Bourdieu, P \& Passeron, J. (1972) La reproducción: elementos para una teoría del sistema de la enseñanza. España: Editorial Popular.

Bradac, J. (1999). Language and social interaction: nature abhors uniformity. En: Research on language and social interaction, $\mathrm{N}^{\circ} 32$ : pp.11-20.

-----. (2002). Extending the domain of speech evaluation: message judgment. En: P. Glenn, C. LeBaron and J. Mandelbaum (Eds). Studies in language and social interaction: in honor of Robert Hopper (pp. 45-56). Lawrence Arlbaum Associates, Mahwah, NJ.

De Beaugrande, R. (1980). Text, Discourse and Process: Toward a Multidisciplinary Science of Texts. N.Y: Longman. 
De Beaugrande, R. y Dressier, W. (1981). Introduction to text linguistics. KY: Longman.

Fairclough, N. (1989). Language and power. London: Longman.

-----, N. (1992). Discourse and social change. Cambridge: Polity Press.

Freud, S. (2004). La interpretación de los sueños. Madrid: Alianza Editorial.

Gimeno, J. (1994): Los materiales: Cultura, pedagogía y control. Contradicciones de la democracia cultural. Ponencia presentada en las IV Jornadas sobre la L.O.G.S.E. Departamento de Pedagogía: Universidad de Granada.

Goldman, L. (1968). El hombre y lo absoluto. Barcelona: Ediciones Península.

Habermas, J. (1997). Conocimiento e Interés. Madrid: Ed. Taurus.

Hart, C. (2007). Critical discourses analysis and metaphor: toward a theorical framework. University of Hertfordshire. Disponible en: http://uhra.herts.ac.uk/bitstream/ handle/2299/4862/901192.pdf?sequence $=1$

Heidegger, M. (2000). Ontología: hermenéutica de la facticidad (Traducción: J. Aspiunza). Madrid: Alianza Editorial. (13 Sesiones de Lecciones en Friburgo, 1923).

Herrero, J. (2002). El análisis de textos. Documento de trabajo. Consultar en: http://www-01.sil. org/training/capacitar/antro/estructuralismo. pdf

Iser, W. (1987). El acto de leer. Madrid: Taurus.

Kedar, L. (Ed.) (1987). Power through discourse. Norwood, NJ: Ablex.

Kramarae, C., Schulz, M. y O’Barr, W. (1984). Language and power. Sage publication, California: Beverly Hills.

Kress, G.(1985). Linguistic processes in sociocultural practice. Victoria: Deakin University Press.
León, E., \& Roncancio, A. (2008). El área de fundamentación contable: una aproximación a partir de sus contenidos $y$ textos. Revista Facultad de Ciencias Económicas: Investigación y Reflexión, 16(2), 189-210. Retrieved February 09, 2017, from http://www. scielo.org.co/scielo.php?script $=$ sci arttext\&pid=S0121-68052008000200013\&1$\mathrm{ng}=\mathrm{en} \& \mathrm{t} \operatorname{lng}=\mathrm{es}$.

Levi-Strauss, C. (2006). Antropología estructural: Mito, sociedad, humanidades. México: Ediciones Siglo XXI.

López, E. (1963). El análisis de contenido, fundamento socio-cultural. En: J. Ibáñez (Coord.), El análisis de la realidad social. Métodos y técnicas de investigación. (461-493) Madrid: Alianza Editorial.

Moreno, S. (2007). Textos y sociedades: didáctica para un análisis contextual de los documentos. Bogotá: Facultad de educación, Pontificia Universidad Javeriana.

Meyer, B. (1984). Dimensiones de texto y el procesamiento cognitivo. En: H. Mandl; N. L. Stein y T. Trabasso (Eds.). El aprendizaje y la comprensión de textos. Hillsdale. N.J: LEA.

Meyer, B. (1985). Análisis estructural de la prosa cientifica: se puede aumentar el rendimiento de resolución de problemas.

Roncancio, Á. y Camargo, D. (2013). El texto inalterable, una mirada a la educación tradicional en la enseñanza de la contabilidad. Ponencia en III Encuentro Nacional de Profesores de Contaduría Pública, Cali - Colombia.

Rumelhart, D. (1977). Comprender y resumir historias breves. En: D. Laberge y S.J. Samuels (Eds). Los procesos básicos en la lectura: Percepción y comprensión. Hillsdale, N. J.: LEA.

Thorndyke, P. (1977). Las estructuras cognitivas en la comprensión y la memoria del discurso narrativo. Psicología Cognitiva. 
Todorov, T. (1996) Los géneros del discurso. Monte Ávila editores Latinoamericana, Venezuela.

Van Dijk, T. (1989) La ciencia del texto. Un enfoque Interdisciplinario. Barcelona: Paidos.

------. (1996). Análisis del discurso ideológico (Traducción: R. Alvarado). En: Revista Versión, UAM, No 6: pp.15-43.

(2003a). Ideología y discurso. Barcelona: Editorial Ariel.

(2003b). Racismo y discurso de las élites. Barcelona: Gedisa.

(2005). Estructuras y funciones del discurso. México: Siglo XXI editores.

Vattimo, G. (1991). Ética de la interpretación. Barcelona: Paidos estudio.

Viloria, N. (2001) Epistemetodología de la ciencia contable en actualidad contable. En: Actualidad Contable, Universidad de los Andes (Venezuela), Vol. 4, No 4: pp. 63-71.

Wodak, R. (Ed.) (1989). Language, power and ideology. Amsterdan: John Benjamins Publishing.

R. (1996). Disorders of discourse: speech barriers and sociolinguistics. London: Longman.

R. (2011). The discourse of politics in action: politics as usual. New York: Palgrave Macmillan.

Wodak, R. y Meyer, M. (2003). Métodos de análisis crítico del discurso. Barcelona: Gedisa. 